\title{
Rio+20: Looking Back at 20 Years of Environmental and Resource Economics
}

\author{
Reyer Gerlagh · Thomas Sterner
}

Accepted: 20 December 2012 / Published online: 10 January 2013

C) Springer Science+Business Media Dordrecht 2013

\begin{abstract}
Twenty years on from the Rio '92 conference, we must face the fact that there have been a few successes but more failures. Scientific complexity, uncertainty, short-termism inherent in politics, the free-rider problem, and issues of fairness are part of the explanation for the lack of progress, but we point to more fundamental motivational problems. It is time to assess our responsibility as economists in the field of environment and resources. Our scientific contribution has been misleading because our models are structurally incapable of addressing major concerns. The cost-benefit test is not fit to assess large-scale resource conservation projects, including climate abatement. This understanding was already present during the Rio '92 summit, but the problems, while identified, have not been resolved twenty years later. The contribution from theory, through the sustainability paradigm of non-decreasing welfare, has turned out ineffective. It does not provide us with tools for designing a better future for our children. Instead, it risks choosing a constant welfare path, with knowledge increasing but natural resources deteriorating, while not properly analyzing the richer
\end{abstract}

Thomas Sterner-Currently on sabbatical working as Visiting Chief Economist at EFD, Environmental Defense Fund in New York. Can be reached there at tsterner@edf.org.

R. Gerlagh $(\bowtie)$

Economics Department, Tilburg University, P.O. Box 90153, 5000 LE Tilburg, The Netherlands e-mail: r.gerlagh@uvt.nl

URL: www.tilburguniversity.edu/nl/webwijs/show/?uid=r.gerlagh/

R. Gerlagh

TSC, Tilburg University, Tilburg, The Netherlands

URL: www.uvt.nl/tsc

R. Gerlagh

CentER, Tilburg University, Tilburg, The Netherlands

URL: http://center.uvt.nl

T. Sterner

Gothenburg University, Vasagatan 1, House E, Room: E-609, P.O. Box 640,

SE 40530 Gothenburg, Sweden

e-mail: thomas.sterner@economics.gu.se 
possibilities for a better future that nature and creativity imply. It is time for our profession to search for a more constructive contribution in theory and practice.

Keywords Rio Earth summit · Sustainability $\cdot$ Climate change

\section{Introduction}

Reyer Gerlagh recently retired as an Associate Editor of ERE to be replaced by former EAERE President Thomas Sterner. In a piece loosely based on Reyer's comments at the most recent EAERE Annual Conference, they unite to provide some leaving, and arriving, comments regarding the political economy of the sustainability debate. They are thankful to Milan Scasny from the EAERE 2012 programme committee for initiating the discussion, and for comments from Ian Bateman, managing editor, and Christian Vossler, associate editor at ERE, although the opinions expressed are solely those of the authors.

\section{Rio+20: Looking Back at 20 Years of Environmental and Resource Economics}

Recently a thousand environmental economists gathered for the 20th European conference in Prague. It was an interesting conference and exciting to see how the profession has developed since the first gathering of just a few dozen pioneers in Venice 1992. Judging by the number of environmental economics articles, by the quality and number of submissions received by this journal and its ranking, by conference attendance, grants received and number of $\mathrm{PhD}$ students - in fact by just about any indicator, the discipline of environmental and resource economics has been outstandingly successful in the last two decades. New associations, new conferences and even new journals appear regularly. There is but one problem: Our academic success can hardly be said to have had its counterpart in real world global environmental improvements. Twenty years on from the Rio ' 92 conference, we must face the fact that the global conferences on sustainable development and climate change are making little progress, and as professionals we must assess our responsibility for this failure. There are successes but also major failures: Although Brazil has made major efforts to slow down deforestation, the rainforests are still in danger of being irreversibly destroyed. When it comes to fish, despite recent advances in catch share management, ocean stocks of many species are at dangerously low levels. And most importantly, though some countries have implemented an emission permits trading scheme, there is no effective global climate agreement in sight. Our resource use is globally far from sustainable, so we must ask; where did we go wrong?

There are of course numerous reasons for our failure. One is scientific complexity and uncertainty; another is the "present bias" or short-termism inherent in politics. This is related to, but still distinct from, a serious effort to understand discounting. Politicians are simply averse to taking on costs in the short run for benefits that will materialize when they have already left office. Selfishness, myopia and pure ignorance are unfortunately not unknown in politics. There are also strong elements of the free-rider problem as a hurdle to reach a cooperative social optimal solution. We know now that many citizens and politicians want to do something about climate change but their concerns are often dominated by perceived and real issues of fairness. The Law of the Seas divided up a large part of the oceans and laid the first foundation for sensible management. This process took many decades simply because the rents at stake were large and the conflicting theories of justice ('how to share') 
were many. These problems are particularly extreme in the case of climate policy and we cannot afford to wait several decades.

We feel that though these issues of cooperation are important, there may be another layer of more fundamental motivational problems. It seems that the majority of the representatives at the international conferences have no sense of urgency when it comes to global resource conservation, which contrasts with the concerns of many natural science researchers studying the loss of global resources.

There is a risk that our scientific contribution here has been misleading because our models are structurally incapable of addressing the concerns: the definitions of optimality and sustainability that we apply in our models are not fit for their purpose, but we don't realize it. Within our profession, there are two reasons generally accepted as arguments for resource preservation. The first is when resource conservation passes a cost-benefit test. The second reason is when the resource loss would result in an unsustainable path, which is jargon for a substantial probability of a strict welfare decline; say, a catastrophe.

The first reason, the cost-benefit test, is very hard to pass for large-scale resource conservation projects, including climate abatement proposals. We all know that global environmental resources, such as rain forests and the climate system, have very slow regeneration rates. ${ }^{1}$ Benefits of current conservation actions materialize after decades, or centuries, and the discount rate plays a major role in the evaluation of such long-term future benefits. The "rate of return" is simply low-and the brazen conclusion is to harvest the resource and invest elsewhere. This understanding was already present during the Rio '92 summit, when Bill Nordhaus and Bill Cline were engaged in a heated debate about whether one should employ normative discounting to give ethically justifiable weights to future generations as favored by Cline, or positive discounting, as favored by Nordhaus, to ensure an efficient combination of investments in environmental quality and capital markets. Twenty years later the issues have not been resolved: how can we reconcile our concerns for subsequent generations with observed returns in capital markets that imply negligible weights for the far future? There have been contributions - think of discounting that is either hyperbolic or at least declining or varies between sectors - but, these have not led to a commonly accepted framework that is easy to use and respects both the ethical dimension and our zeal for efficiency.

This is illustrated by the attacks on the work of Cline (1992) and subsequently Stern (2006). The positive economists told us that low rates of discount are contradictory to preferences as revealed by savings decisions. ${ }^{2}$ For many in our profession, this was sufficient to discard the analyses of Cline and Stern. Even those who have some sympathy with their resource concerns generally feel obliged to acknowledge that low discount rates must also mean high capital investment rates. Resource conservation plus low overall investments would imply different rates of return for natural resources and capital investments, and that would be a sin against our efficiency criterion. ${ }^{3}$

Put in everyday terms, these critics are asking: If we care so much for the future (as is reflected in a discount rate of say just one percent) then surely we should leave no stone unturned in order to improve the welfare of future generations. Why not, in that case, increase the savings rate and thus growth rate and thereby leave a richer world to our descendants.

\footnotetext{
1 The long time horizon is characteristic for, but not uniquely restricted to global environmental problems. Similar problems in evaluation arise when we study nuclear and genetic modification programs.

2 This and the following lines are, we acknowledge, a very brief presentation of the arguments. An elaborate, well-written presentation of most of the arguments against 'correcting' the discount rate is found in Nordhaus (1997).

3 To be sure, the argument does not imply that discount rates must be the same between sectors. They can be different when relative scarcity changes over time. For discussion see Sterner and Persson (2008).
} 
So, when Cline and Stern couldn't find arguments for more capital investments (apart from resource conservation), many economists found it increasingly difficult to support low discount rates (and thereby strong policies to combat climate change).

The more conventional approach is to calculate "efficient" resource programs using capital returns to motivate high rates of discounting. These programs often conclude that the costs of substantial resource conservation exceed the net present value of benefits. For example, a scenario with a $5^{\circ} \mathrm{C}$ temperature increase worldwide occurring after 2,200 (which could generate catastrophic impacts on affected generations) can, in this literature, be presented as optimal without any second thoughts.

An alternative strategy is to use cost-effectiveness analysis. This literature presupposes some environmental target, such as the $2^{\circ} \mathrm{C}$ maximum, and then calculates the least-cost path of attaining that objective. A problem for this literature is that a similar critique can be applied as to differential discounting: we are told that these targets are arbitrary, precisely because they lack the backing of a real cost-benefit analysis. Thus, adhering to these goals is not necessarily beneficial in the sense of increasing welfare.

If ethically motivated "low" discount rates fail, the only alternative approach many researchers see is to use the sustainability paradigm of non-decreasing welfare as a reason to protect the environment. However, non-decreasing welfare is an ineffective argument. It underestimates our human potential to increase welfare, and it is in danger of sacrificing nature by treating the beauty of nature and consumption as substitutes. Imagine our present society bargaining with future generations. We have two goods to offer: they can inherit knowledge and manufactured wealth — the fruits of our labor and creativity — or we can leave them nature's richness. Of course we can also leave them both, wealth and nature, but there is a cost-our present consumption and economic growth would be somewhat lower. Standard economic analyses typically assume we face a bright future of economic growth: a couple of percent per year for the foreseeable future. ${ }^{4}$ Costs in these models show up as decreased growth rates. As shown by Azar and Schneider (2002), the reduction in growth will be small. Even if the cost of $\mathrm{CO}_{2}$ abatement rises to $5 \%$ of global income per year by the end of this century, this is dwarfed by expected economic growth in the long run. The total value of this cost might be in the trillions of Euros, but another way of expressing the same cost is that it would take 101 or 102 years instead of 100 years before we get five or ten times as rich. Expressed this way, many people prefer the slightly lower growth rate to avoid the risk of losing irreversible properties of nature, even though the discounted cost may be a very large number when expressed in euros. ${ }^{5}$

In this context, the sustainability paradigm is not much of a help, because if we bequeath both manufactured and nature wealth to the future, they would be better off than we are today. The trouble is the common definition of sustainability, which requires that future generations should not be worse off than we are. The paradigm does not provide us with tools for designing a better future for our children. When we define sustainability as non-decreasing welfare, and if this condition is binding, it means literally that the path chosen will be one of constant welfare. And as future generations will enjoy the benefits of all our innovations, constant welfare must mean that they are not allowed to enjoy the benefits of nature's richness in

\footnotetext{
4 This growth is in many calculations the most important reason why we discount; future citizens will be so rich that a given cost will appear small to them. More formally this is seen in the Ramsey formula where the discount rate is equal to time preference plus the growth rate multiplied by the elasticity of marginal utility $\delta+g \eta$.

5 We do not say that society must prefer stringent climate policies. The purpose is to make clear that, thanks to human ingenuity, stringent climate policy is compatible with sustained economic growth, and thus-as we will see below-non-decreasing welfare cannot be invoked to justify stringent climate policies.
} 
addition to that but must themselves conserve the resources necessary to support the welfare of their heirs. It follows from straight mathematics. Assume that welfare $W$ increases with knowledge, $H$, and with nature's richness, $N .{ }^{6}$ Furthermore, let us assume that knowledge increases so that $H$ increases, and that under a binding sustainability condition, welfare, $W(H, N)$, is constant. It immediately follows that nature, $N$, declines. The sustainability paradigm risks choosing a constant welfare path, with natural resources deteriorating, while not properly analyzing the richer possibilities for a better future that nature and creativity imply. The economists' sustainability paradigm, when effective, leads to the destruction or at least degradation of nature's richness as the perfect sustainable solution. ${ }^{7}$

To conclude, the global conferences on sustainable development, Rio, Rio+20, and all the others, are steps; in the right direction maybe, but very small steps and they have not delivered much. Maybe we as economists share some of the responsibility for this failure? We have consistently advised our representatives that the optimal plan is to tinker with the margins; ${ }^{8}$ papers show that it can be optimal to destroy resources but delay their destruction by a few decades so that the future would be rich enough and welfare would not need to decline. The only reason for a more stringent resource conservation program that we economists can envisage is if there is a real danger of catastrophe. Such a case is hard to prove. ${ }^{9}$ Without a catastrophe the typical economist's advice is to do close to nothing. The outcomes of such international summits are just that. It is time for our profession to search for a more constructive contribution in theory and practice.

\section{References}

Azar C, Schneider S (2002) Are the economic costs of stabilising the atmosphere prohibitive? Ecol Econ 42:73-80

Cline WR (1992) The economics of global warming. Institute for International Economics, Washington, DC

Gerlagh R, van der Zwaan BCC (2002) Long-term substitutability between environmental and man-made goods. J Environ Econ Manag 44:329-345

Nordhaus WD (1997) Discounting in economics and climate change. Clim Change 37:315-328

Stern N (2006) The economics of climate change: the Stern review. Cambridge University Press, Cambridge Sterner T, Persson UM (2008) An Even Sterner review: introducing relative prices into the discounting debate.

Rev Environ Econ Policy 2(1):61-76

\footnotetext{
6 For convenience, we don't specify knowledge and manufactured capital apart. Modern growth theories have taught us that knowledge (including technology) is the ultimate driver for both manufactured capital and output.

7 If manufactured goods are assumed a good long-term substitute for nature, as common in many models (!), then constant utility plus continued knowledge growth implies full exhaustion of nature. See Gerlagh and van der Zwaan (2002) for discussion.

8 This is partly a communication problem. On the one hand the literature shows substantial effort is required to decarbonize the economy. On the other hand these efforts are or can appear 'small' in view of their effects on temperature change and long-run economic growth.

9 As a case in point, the uncertainty with respect to the climate sensitivity has not come down, and few natural scientists believe it will in the coming decades.
} 